\title{
Glycaemic index and glycaemic load values of commonly consumed foods in the United Arab Emirates
}

\author{
Ayesha S. Al Dhaheri ${ }^{1 *}$, C. Jeyakumar K. Henry ${ }^{2}$, Maysm N. Mohamad ${ }^{1}$, Eric O. Ohuma ${ }^{3,4}$, \\ Leila Cheikh Ismail ${ }^{5}$, Fatima T. Al Meqbaali ${ }^{1}$ and Amjad H. Jarrar ${ }^{1}$ \\ ${ }^{1}$ Nutrition and Health Department, College of Food and Agriculture, United Arab Emirates University, Al Ain, PO Box 15551, \\ United Arab Emirates \\ ${ }^{2}$ Department of Biochemistry, Yong Loo Lin School of Medicine, Singapore City, 117597, Singapore \\ ${ }^{3}$ Centre for Statistics in Medicine, Botnar Research Centre, University of Oxford, Oxford OX3 7LD, UK \\ ${ }^{4}$ Nuffield Department of Medicine, Centre for Tropical Medicine and Global Health, University of Oxford, Oxford OX3 $7 F Z$, UK \\ ${ }^{5}$ Nuffield Department of Obstetrics and Gynaecology and Oxford Maternal and Perinatal Health Institute, Green Templeton \\ College, University of Oxford, Oxford OX3 9DU, UK
}

(Submitted 5 October 2016 - Final revision received 5 April 2017 - Accepted 6 April 2017 - First published online 23 May 2017)

\section{Abstract}

Glycaemic index (GI) and glycaemic load (GL) values of some commonly consumed foods in the United Arab Emirates were determined with an aim of adding these values to the existing international table of GI and GL values. In all, eighteen test foods categorised into breads ( $n$ 5), entrée dishes ( $n$ 3), main dishes ( $n 5$ ) and sweet dishes ( $n$ 5) were tested. For each test food, at least fifteen healthy participants consumed 25 or $50 \mathrm{~g}$ available carbohydrate portions of a reference food (glucose), which was tested three times, and a test food after an overnight fast, was tested once, on separate occasions. Capillary blood samples were obtained by finger-prick and blood glucose was measured using clinical chemistry analyser. A fasting blood sample was obtained at baseline and before consumption of test foods. Additional blood samples were obtained at 15, 30, 45, 60, 90 and $120 \mathrm{~min}$ after the consumption of each test food. The GI value of each test food was calculated as the percentage of the incremental area under the blood glucose curve (IAUC) for the test food of each participant divided by the average IAUC for the reference food of the same participant. The GI values of tested foods ranged from low ( 55 or less) to high ( 70 or more). The GI values of various breads and rice-containing dishes were comparable with previously published values. This study provides GI and GL values of previously untested traditional Emirati foods which could provide a useful guide on dietary recommendations for the Emirati population.

Key words: Glycaemic index: Glycaemic load: Emirati foods: Carbohydrates: Diabetes

The glycaemic index (GI) was introduced in 1981 after observing the dramatic variation in blood glucose response after the ingestion of carbohydrate-rich foods ${ }^{(1)}$. It is defined as 'the incremental area under the blood glucose response curve (IAUC) of a $50 \mathrm{~g}$ carbohydrate portion of a tested food expressed as a percent of the response to the same amount of carbohydrate from a reference food taken by the same participant (white bread or glucose), on a different day, ${ }^{, 2)}$.

Initially, GI was only utilised in the prevention and management of diabetes ${ }^{(3)}$. Further, epidemiological and interventional studies investigated other important implications of GI for prevention and treatment of obesity ${ }^{(4)}, \mathrm{CVD}^{(5)}, \mathrm{CHD}^{(6)}$ and certain forms of cancer ${ }^{(7)}$. Recent scientific evidence indicates a possible role of low-GI diets in the treatment and prevention of diabetes mellitus $(\mathrm{DM})^{(8)}$, obesity $^{(9)}$, hyperlipidaemia and $\mathrm{CVD}^{(5)}$, by improving insulin sensitivity ${ }^{(10)}$, regulating appetite ${ }^{(11)}$, lowering fasting insulin and C-reactive protein levels ${ }^{(12)}$, reducing total cholesterol and LDL-cholesterol ${ }^{(13)}$, and regulating blood pressure ${ }^{(14)}$.

Moreover, the FAO of the UN and the WHO have also validated the use of GI for the classification of carbohydratecontaining foods ${ }^{(2)}$, and recommend its use along with food composition tables to guide better food choices. However, several factors like cooking method, food particle size, food processing and starch structure could alter the GI of foods significantly $^{(15)}$. The GI of the same food has been shown to vary in different countries, regions or manufacturers. Emirati traditional foods differ from other cuisines mainly in the ingredients used and the cooking method (e.g. prolonged cooking, mixing all ingredients in one pot), thus it is hypothesised that traditional Emirati foods have different GI values compared with similar foods in the Gulf region.

Abbreviations: GI, glycaemic index; GL, glycaemic load; IAUC, incremental area under the blood glucose response curve.

*Corresponding author: A. S. Al Dhaheri, fax +97137671596, email ayesha_aldhaheri@uaeu.ac.ae 
The first international table of GI was published in $1995^{(16)}$ and included 565 separate entries. Updated versions of the GI tables were published in $2002^{(17)}$ and the most recent in $2008^{(18)}$. The latter includes the GI and glycaemic load (GL) values of 2487 individual food items ${ }^{(18)}$. However, the majority of the published GI and GL values are from Western countries and not much data are available about the GI values of Arabic foods, particularly Emirati foods. Therefore, the main aim of the this study is to provide reliable values of GI and GL of some commonly consumed foods in the United Arab Emirates.

\section{Methods}

\section{Participants}

A total of eighty-eight healthy participants (thirty-seven males and fifty-one females) from United Arab Emirates University (UAEU), students and staff, were voluntarily recruited to take part in the study. Characteristics of the participants are presented in Table 1. Recruitment was carried out via posters distributed around the university campus and email invitations. All participants were informed about the details of the study, study protocol and were given a chance to ask questions. Informed written consent was obtained from all participants before taking part in the study. Participants were excluded if they were $<18$ or $>40$ years; BMI value was $\geq 25$ or $<18.5 \mathrm{~kg} / \mathrm{m}^{2}$; fasting blood glucose value of $>6.1 \mathrm{mmol} / \mathrm{l}$ or having a known history of impaired glucose tolerance or DM.

Participants were asked to complete a health-screening questionnaire before taking part to confirm that they met the inclusion criteria. Anthropometric measurements were conducted in the Nutrition and Health Department laboratory at UAEU before recruitment to confirm whether a participant met the inclusion criteria. All measurements were obtained at the fasting state (i.e. during active 12-h fast) while wearing minimal clothing (as local culture permits) and no shoes. Height was recorded to the nearest $1 \mathrm{~cm}$ using a stadiometer (Seca Ltd) and waist circumference $(\mathrm{cm})$ was measured using a measuring tape. Body weight $(\mathrm{kg})$, fat mass and fat-free mass were measured using Tanita Segmental Body Composition Analyser (TBF-410 MA; Tanita). BMI was calculated as weight (kg) divided by the square of the height $\left(\mathrm{m}^{2}\right)$.

The present study was conducted according to the guidelines laid down in the Declaration of Helsinki and all procedures

Table 1. Anthropometric characteristics of the study population (Mean values and standard deviations for eighty-eight participants, $42 \%$ males to $58 \%$ females)

\begin{tabular}{lcr}
\hline & Mean & \multicolumn{1}{c}{ SD } \\
\hline Age (years) & 22.1 & 3.58 \\
Height $(\mathrm{m})$ & 1.60 & 0.05 \\
Weight $(\mathrm{kg})$ & 56.89 & 6.04 \\
BMl $\left(\mathrm{kg} / \mathrm{m}^{2}\right)$ & 22.15 & 1.89 \\
Waist circumference (cm) & 75.06 & 15.84 \\
Fat mass (\%) & 28.81 & 4.64 \\
Fat-free mass (\%) & 65.79 & 12.89 \\
Fasting blood glucose (mmol/l) & 4.86 & 0.42 \\
\hline
\end{tabular}

involving human subjects were approved by the United Arab Emirates University Scientific Research Ethics Committee (ref. no. 516/09).

\section{Test foods}

A total of eighteen different foods commonly consumed in the UAE and categorised into breads ( $n$ 5), entrée dishes ( $n$ 3), main dishes $(n 5)$ and sweet dishes ( $n 5)$ were tested. The test foods were purchased from popular restaurants in the UAE that specialise in Emirati cuisine and have standardised recipes. Table 2 lists the major ingredients of the test foods.

\section{Analytical methods}

Proximate analyses including moisture, protein, fat, fibre and ash content were conducted at the Nutrition and Health Department laboratories of the university following standard methods of the Association of Official Analytical Chemists ${ }^{(19)}$. Total carbohydrate and available carbohydrate content were estimated by difference ${ }^{(20)}$. The energy content was calculated by multiplying the amount of protein, carbohydrate and fat by factors of 4, 4 and 9, respectively ${ }^{(21)}$. Each test was performed in triplicate and the results averaged to minimise possible systematic and random experimental errors.

\section{Study protocol}

The procedure for GI measurement was adapted from Wolever et al. ${ }^{(22)}$ and Brouns et al. ${ }^{(15)}$ and is recommended by Food and Agriculture Organization/World Health Organization ${ }^{(2)}$. Testing was repeated in at least fifteen participants for each test food. Prior to the test day, participants were requested to limit their intake of caffeinated drinks and avoid involvement in intense exercise. Participants were asked to fast for $12 \mathrm{~h}$ (overnight) the night before each test.

Using the randomised cross-over design, participants tested the reference food three times and each test food for one time only. Food testing was carried out on separate occasions with at least 1-d gap between measurements to minimise any carryover effects. The reference food provided was glucose powder (glucose dextrose monohydrate) dissolved in $200 \mathrm{ml}$ of water. Test foods were tested in equivalent available carbohydrate amounts ( 25 or $50 \mathrm{~g}$ ) as per the reference food and were also served with $200 \mathrm{ml}$ water. Test foods were purchased $1 \mathrm{~d}$ before the test, then heated in the morning of the test. Participants were encouraged to consume the reference or test foods within $15 \mathrm{~min}$ and to minimise physical activity during the testing time. Available carbohydrate content was used to determine the experimental portion ( $\mathrm{g}$ ) that would provide 50 or $25 \mathrm{~g}$ of available carbohydrates from each test food. The majority of test foods were tested against $50 \mathrm{~g}$ of available carbohydrate. Nevertheless, if the serving size was found to be too large to ingest comfortably, this test food was tested against $25 \mathrm{~g}$ of available carbohydrate ${ }^{(15)}$. In this study, only Chami (cottage cheese) was tested against 25 gof available carbohydrate due to its very low carbohydrate content $(5 \cdot 44 / 100 \mathrm{~g})$. 


\section{Blood glucose measurements}

Before blood collection, participants were asked to warm their hand to increase blood flow. A fasting blood sample (0 min) was then obtained (following the WHO 2010 guidelines for withdrawing blood ${ }^{(23)}$ ) before consumption of each food and additional blood samples obtained at 15, 30, 45, 60, 90 and 120 min after the consumption of each food. Capillary blood was collected from the third finger on the left hand using the OneTouch ${ }^{\circledR}$ UltraSoft ${ }^{\mathrm{TM}}$ Adjustable Blood Sampler (Johnson and Johnson). Squeezing of the finger was avoided to minimise plasma

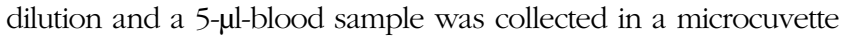
by capillary action. Blood glucose was measured using the HemoCue Glucose 201+ portable system (HemoCue ${ }^{\circledR}$ Ltd). Calibration of the blood glucose meters was done daily according to the manufacturers' instructions.

\section{Calculation of glycaemic index and glycaemic load}

The IAUC was geometrically calculated ignoring the area beneath the baseline ${ }^{(22)}$. The IAUC for each test food consumed by each subject was expressed as a percentage of the mean IAUC for the reference food consumed by the same subject:

$$
\begin{aligned}
\mathrm{GI}= & (\mathrm{IAUC} \text { for the test food containing }(\mathrm{X}) \mathrm{g} \text { of available } \\
& \text { carbohydrates }) /(\text { IAUC of a reference food with } \\
& \text { an equal available carbohydrates portion }) \times 100 .
\end{aligned}
$$

The overall GI of each test food was calculated as the mean for the whole group.

The GL of a serving of each test food was calculated by the following formula ${ }^{(24)}$ :

$$
\begin{aligned}
\mathrm{GL}= & (\text { GI of test food } \times \text { amount of available carbohydrate } \\
& \text { in a serving of test food }(\mathrm{g})) / 100 .
\end{aligned}
$$

The serving size of each test foods was taken from the Photographic Atlas of Food Portions for the Emirate of Abu Dhabi $^{(25)}$.

\section{Statistical analysis}

A total of fifteen participants or more were used for GI testing of a single food which is more than the minimum requirement recommended by the ISO 26642:2010 standard for GI testing ${ }^{(26)}$. All statistical analyses were performed using Minitab software for Windows version 16 (Minitab Inc.).

\section{Results}

The proximate analyses data were expressed as means and standard derivations (Table 3). Information from Table 3 was essential for calculating the amount of available carbohydrate $(\mathrm{g} / 100 \mathrm{~g})$ in each test food.

The GI and GL values for all tested foods are given in Table 4. GI values of carbohydrate foods are classified as low $(\leq 55)$, medium (56-69 inclusive) and high ( $\geq 70)$ GI foods. The four groups of food included in this study (breads, entrée, main and 
Table 3. Proximate analysis of eighteen traditional foods commonly consumed in the United Arab Emirates ( $\mathrm{g} / 100 \mathrm{~g}$ on a fresh weight basis) (Mean values and standard deviations)

\begin{tabular}{|c|c|c|c|c|c|c|c|c|c|c|c|c|c|c|c|c|}
\hline \multirow[b]{2}{*}{ Test food } & \multicolumn{2}{|c|}{ Moisture (g) } & \multicolumn{2}{|c|}{ Protein $(\mathrm{g})$} & \multicolumn{2}{|c|}{ Fat (g) } & \multicolumn{2}{|c|}{ Ash (g) } & \multicolumn{2}{|c|}{ Fibre (g) } & \multicolumn{2}{|c|}{ Carbohydrates (g) } & \multicolumn{2}{|c|}{ Energy (kJ) } & \multicolumn{2}{|c|}{ Energy (kcal) } \\
\hline & Mean & SD & Mean & SD & Mean & SD & Mean & SD & Mean & SD & Mean & SD & Mean & SD & Mean & SD \\
\hline Arabic bread & $25 \cdot 12$ & 0.34 & 9.45 & 0.05 & $1 \cdot 15$ & 0.04 & 0.68 & 0.04 & 0.13 & 0.01 & 63.61 & 0.38 & 1265.91 & 4.18 & 302.56 & $1 \cdot 14$ \\
\hline Regag bread & 21.93 & 0.79 & 10.49 & 0.07 & 0.46 & 0.01 & 1.88 & 0.02 & 1.23 & 0.14 & $65 \cdot 25$ & 0.73 & 1284.66 & 13.60 & 307.04 & 3.25 \\
\hline Chebab bread & $35 \cdot 70$ & $2 \cdot 15$ & 7.08 & 0.35 & 9.07 & 0.83 & 1.07 & 0.07 & 1.20 & 0.77 & 47.08 & 1.51 & 12478.92 & 48.28 & 298.26 & 11.54 \\
\hline Muhalla bread & $15 \cdot 63$ & 5.91 & $10 \cdot 34$ & 0.82 & $4 \cdot 24$ & 1.00 & 1.59 & 0.27 & 0.54 & 0.03 & $68 \cdot 20$ & 4.78 & $1474 \cdot 23$ & 111.00 & $352 \cdot 35$ & 26.53 \\
\hline Khameer bread & 18.43 & 6.42 & $10 \cdot 45$ & 0.75 & $12 \cdot 69$ & $2 \cdot 13$ & 1.69 & 0.27 & 1.81 & 0.31 & $56 \cdot 74$ & 3.42 & $1602 \cdot 35$ & $146 \cdot 73$ & 382.97 & 35.07 \\
\hline Fendal & 62.48 & 0.20 & 1.86 & 0.02 & 0.57 & 0.01 & 0.55 & 0.06 & $2 \cdot 91$ & 0.05 & 34.54 & 0.24 & $630 \cdot 57$ & 3.97 & $150 \cdot 71$ & 0.95 \\
\hline Chami & $77 \cdot 25$ & 0.23 & 15.48 & 0.28 & 0.66 & 0.17 & 1.17 & 0.18 & 0.12 & $0 \cdot 10$ & 5.44 & 0.49 & 374.97 & $3 \cdot 10$ & 89.62 & 0.74 \\
\hline Habba Hamra & $80 \cdot 24$ & 1.60 & 1.23 & 0.97 & 1.84 & $1 \cdot 31$ & 0.48 & 0.05 & 0.25 & 0.06 & $16 \cdot 21$ & 1.22 & $361 \cdot 20$ & 53.14 & $86 \cdot 33$ & $12 \cdot 70$ \\
\hline Harees, beef & $77 \cdot 70$ & 1.63 & 5.55 & 0.38 & 2.43 & 0.84 & 1.01 & 0.17 & 5.56 & 0.86 & $13 \cdot 30$ & 0.92 & $407 \cdot 10$ & $45 \cdot 31$ & $97 \cdot 30$ & 10.83 \\
\hline Thareed, beef & 78.40 & 0.55 & 7.04 & 0.23 & $2 \cdot 13$ & 0.08 & 0.31 & 0.01 & 1.26 & $0 \cdot 19$ & $12 \cdot 12$ & 0.34 & $400 \cdot 91$ & $10 \cdot 71$ & $95 \cdot 82$ & 2.56 \\
\hline Biryani, chicken & $63 \cdot 26$ & $1 \cdot 34$ & 11.55 & 0.86 & $3 \cdot 28$ & 0.42 & $1 \cdot 26$ & 0.12 & 0.96 & 0.45 & $20 \cdot 65$ & 1.06 & $662 \cdot 49$ & $15 \cdot 56$ & $158 \cdot 34$ & 3.72 \\
\hline Machbous, fish & $68 \cdot 26$ & $2 \cdot 24$ & 6.96 & 1.56 & 1.98 & 0.29 & 1.20 & 0.12 & 3.60 & 0.56 & 21.60 & 0.45 & 552.46 & $42 \cdot 30$ & 132.04 & $10 \cdot 11$ \\
\hline Arseyah & $86 \cdot 66$ & 0.34 & $2 \cdot 24$ & 0.04 & 0.88 & 0.10 & 0.11 & 0.01 & 0.26 & 0.01 & $10 \cdot 11$ & 0.46 & 239.93 & 3.97 & $57 \cdot 32$ & 0.95 \\
\hline Khabisa & 24.91 & 4.01 & $5 \cdot 38$ & 0.87 & $10 \cdot 54$ & 1.60 & 0.32 & 0.08 & $2 \cdot 72$ & 0.41 & $58 \cdot 85$ & 4.56 & 1471.68 & $67 \cdot 45$ & $351 \cdot 74$ & $16 \cdot 12$ \\
\hline Leqemat & $23 \cdot 26$ & 1.72 & 7.29 & 0.28 & $22 \cdot 80$ & 2.09 & 1.02 & 0.10 & 1.45 & 0.34 & 45.63 & 1.12 & 1744.35 & 70.58 & 416.91 & 16.87 \\
\hline Batheetha & $16 \cdot 40$ & 0.14 & $5 \cdot 81$ & 0.04 & 9.54 & 0.09 & $1 \cdot 14$ & 0.07 & $6 \cdot 12$ & 0.44 & $67 \cdot 11$ & 0.03 & 1579.71 & 3.72 & 377.56 & 0.89 \\
\hline Khan & 21.57 & 2.08 & $6 \cdot 72$ & 0.20 & $30 \cdot 32$ & 1.91 & 0.60 & 0.10 & 1.16 & 0.28 & & 0.77 & 1936.86 & 75.52 & 462.92 & 18.05 \\
\hline Balalet & 55.67 & 3.50 & 2.40 & 0.26 & 1.72 & 0.58 & 0.12 & 0.04 & $12 \cdot 20$ & 1.31 & 40.09 & $3 \cdot 19$ & 776.05 & 66.48 & $185 \cdot 48$ & 15.89 \\
\hline
\end{tabular}

dessert) produced a wide range of GI values ranging from 42 in Harees to 77 in Muhalla bread.

Seven test foods had low GI (Chebab bread, Khameer bread, Harees (beef), Biryani (chicken), Leqemat, Khanfaroosh and Habba Hamra), six were classified as medium GI (Arabic bread, Chami, Machbous (fish), Khabisa, Batheetha and Balalet) and five showed high GI values (Regag bread, Muhalla bread, Fendal, Thareed (beef) and Arseyah).

\section{Discussion}

We tested the GI of eighteen traditional Emirati foods, that is five breads, three entrée dishes, five main dishes and five desserts. Among the tested breads, Muhalla bread had the highest GI (mean GI =77) and Khameer bread had the lowest GI (mean GI = 47). Of the three entrée dishes tested Fendal was classified as a high-GI food (mean GI=74), Chami as a medium-GI food (mean GI =60) and Habba Hamra as a low-GI food (mean GI =47). Two of the main dishes had a high GI (Thareed and Arseyah), two had a low GI (Harees and Biryani) and one main dish had a medium GI (Machbous). The GI values of sweet dishes tested in the present study ranged from 44 in Leqemat to 67 in Khabisa.

Several factors are known to alter the glycaemic response of food, that is, presence of macronutrients such as fat and protein, type of starch, processing method, and addition of acids, sugars, gelling fibre or amylase inhibitors ${ }^{(27)}$. Other factors include the degree of chewing, concentration of amylase in the gut, presence of other food components in the gut, amount of the insulin response and rate of gastric emptying ${ }^{(28)}$

Bread is a staple food that is prepared usually by baking a dough of flour (wheat, rye, rice, oat or barley) and water. Two breads were classified as high GI - Regag bread (mean GI = 76) and Muhalla bread (mean GI $=77$ ) - and the main dish containing bread was also high in GI, that is - beef Thareed (mean GI =74). The 2008 international tables of GI and GL reported a mean GI value of 75 (high) for white wheat bread and 70 (high) for unleavened wheat bread ${ }^{(18)}$. Regag and Muhalla breads are unleavened wheat breads with an increased surface area and thinness leading to an increase in the availability of starch for digestion and therefore higher GI response (mean GI $=76$ and 77 , respectively) ${ }^{(29,30)}$ compared with white wheat bread. The GI values of Regag and Muhalla breads reported in this study are comparable with the GI value of Tanour bread (mean GI $=81$ ) reported by Hassan et $a l{ }^{(31)}$. Tanour bread is also a thin type of bread with a large surface area and is usually baked on a crepe oven.

White Arabic wheat bread, also referred to as 'Lebanese bread', had a mean GI value of 67 (medium). Similarly, Ali et al. evaluated the GI of eight different types of traditional Omani wheat breads and reported a GI value of 63 (medium) for white Lebanese wheat bread ${ }^{(32)}$. The 2008 international tables of GI and GL reported a mean GI value of 57 for white Pita bread. However, Arabic bread and Pita bread are not the same type of bread, as they differ in thickness and size. Other factors like the type of oven used for baking (gas oven or masonry oven), temperature of the oven and the amount of yeast added could affect the GI. Arabic bread loaf tends to be thinner, larger, leavened and baked in a masonry oven. The effect of sourdough fermentation of leavened baked breads on the GI has been previously reported ${ }^{(33-36)}$. The effect of sourdough fermentation on the GI of bread was thought to be due to the synthesis of lactic acid which in turn lowers the rate of starch digestion $^{(33)}$, synthesis of acetic and propionic acids, causing a reduction in the gastric emptying rate ${ }^{(34)}$, or the synthesis/ release of amino acids and peptides, resulting in better regulation of glucose metabolism ${ }^{(35)}$. This could explain the lower GI values of Khameer bread (mean GI $=47$ ), Chebab bread (mean GI =54) and Arabic bread (mean GI =67) which are considered leavened breads (fermented by yeast) compared with other breads in this study. 
Chebab bread and Khameer bread showed low GI values, which might be due to their high protein $(7.08$ and $10.45 \mathrm{~g} /$ $100 \mathrm{~g}$, respectively) and fat content $(9.07$ and $12.69 \mathrm{~g} / 100 \mathrm{~g}$, respectively), and the use of whole-grain wheat flour. Studies suggest that adding fat and protein to foods containing carbohydrates could possibly reduce their glycaemic response and decrease their overall $\mathrm{GI}^{(37,38)}$. It has been proposed that protein stimulates greater gastric inhibitory peptide and higher insulin responses, which in turn lowers the postprandial peak of glucose and reduces the glycaemic response of high-GI foods ${ }^{(39)}$. High fat content was shown to delay the rate of gastric emptying, thus reducing the rate of glucose digestion and absorption ${ }^{(40)}$. Moreover, using whole-grain wheat flour instead of refined wheat flour for the preparation of bread is recommended in order to reduce their high GI values. The presence of dietary fibre in foods could also delay its glycaemic response, as it contributes to slower nutrient absorption and delayed transit time in the small intestines ${ }^{(22,41)}$.

The GI values of sweet potatoes reported in the literature ranged from 44 (low) to 78 (high) ${ }^{(17)}$ depending on the variety, maturity, cooking method (baking, steaming, roasting, frying or boiling), cutting method (cubing, peeling, mashing or slicing), cooling process and storage conditions (period and temperature $)^{(42-45)}$. In the current study, Fendal (boiled Beauregard sweet potato, red-orange skin and orange flesh) had a GI of 74 (high). Jenkins et al. ${ }^{(1)}$ found that sweet potato from Canada had a GI of 48 while sweet potato (Ipomoea batatas) in Australia had a GI of 44 only ${ }^{(46)}$. However, in New Zealand, Perry et $\mathrm{al}^{(47)}$ reported a GI of 77 for Kumara (sweet potato) ${ }^{(47)}$. In contrast, the GI for sweet potato that has been peeled, cubed, boiled (in salted water for $15 \mathrm{~min}$ ) was $59^{(48)}$. According to the 2008 international tables of GI and GL values, the mean GI value for boiled sweet potato is $63^{(18)}$, however, Fendal is an unpeeled whole Beauregard sweet potato boiled in water with the addition of dates to the boiling water as a sweetener which might explain its high GI. It is recommended to precook potatoes and consume them cold (potato salad, for example) or reheated ${ }^{(42,49)}$, or consuming potatoes with other ingredients such as acetic acid (vinegar) ${ }^{(50)}$, vinaigrette dressing (vinegar and olive oil added to potato salad) ${ }^{(51)}$ or topping baked potatoes with Cheddar cheese ${ }^{(40)}$ to lower its glycaemic response.

Chami is a cottage cheese dish which is highly consumed among the Emirati population on a daily basis as part of breakfast (with bread) or as a snack (with dates), therefore it was essential to measure its GI value. Although Chami is not a major source of carbohydrates, its mean GI value was found to be 60. Another milk-based traditional food is the Habba Hamra, which is prepared by soaking red seeds in hot evaporated milk. The low mean GI of 47 for Habba Hamra was expected, as the literature indicated low GI for full-fat milk, ranging from 11 to $46^{(17,18)}$.

Rice is the main staple food and energy source for almost half of the world's population. Hence, it has significant nutrition and health implications. Many studies on rice and rice products led to the conclusion that rice should generally be classified as a high-GI food ${ }^{(52-55)}$. However, many factors could affect the GI of rice and rice products, including rice variety and starch 
content (amylose and amylopectin), cooking, processing, cooling, soaking, fibre content and particle size ${ }^{(55)}$. Moreover, rice is hardly ever consumed on its own; it is often accompanied with other foods such as pulses, legumes, vegetables, seafood, nuts and meats, which could alter the overall GI of the mixed meal. In this study, Biryani, Machbous and Arseyah (mixed rice dishes (rice with chicken or fish)) were found to have low (52), medium (60) and high (72) GI values. The high protein content in Biryani $(11.55 \mathrm{~g} / 100 \mathrm{~g}$ ) along with added vegetables (onion, garlic and pepper) could explain its low GI. In Sri Lanka, parboiled Mottai Karupan red rice showed a mean GI value of 47 when it was consumed with Amaranthus leaf curry, and 56 for parboiled rice with soya meat gravy ${ }^{(56)}$. The addition of acidic condiments (vinegar or pickles), emulsifiers, dairy products (milk, cheese and yogurt), vegetables, pulses and viscous fibre seems to decrease the GI of mixed meals containing rice ${ }^{(55)}$. High GI value of Arseyah might be due to prolonged cooking (boiling for $2 \mathrm{~h}$ ) and blending the rice while being cooked. These cooking methods result in increasing the gelatinisation and digestibility ${ }^{(57,58)}$. of rice, as well as having an impact on the glycaemic response of the mixed meal ${ }^{(55)}$. Harees is a traditional dish with a porridge-like consistency; it is prepared from whole wheat with meat (beef or chicken) ${ }^{(59)}$. The GI value of Harees was the lowest among the traditional dishes studied (mean GI $=42$ ) and this could be explained by its high amount of dietary fibre $(5.56 \mathrm{~g} / 100 \mathrm{~g})^{(22,41)}$. Similarly, the high fat content in Legemat and Khanfaroosh $(22.8$ and $30.32 \mathrm{~g} / 100 \mathrm{~g}$, respectively) might be the reason behind their low GI values (mean GI $=44$ and 45, respectively). Food choice should not solely depend on the GI value of the food, as high fat content especially saturated fats as in the case of Khanfaroosh and Legemat $(13.520$ and $9.586 \mathrm{~g} / 100 \mathrm{~g}$, respectively) - defeats the purpose of choosing low-GI foods. Batheetha is a date paste made out of Khalas date fruit mixed with white wheat flour, ghee, sugar, cardamom and cinnamon. Various studies have reported the low GI value of date fruit ${ }^{(60,61)}$. In 2011, Alkaabi et $a{ }^{(61)}$ reported the mean GI of Fara'd, Lulu, Bo ma'an, Dabbas and Khalas dates tested in thirteen healthy individuals to be $54 \cdot 0,53 \cdot 5,46 \cdot 3,49 \cdot 1$ and $55 \cdot 1$, respectively. In the current study, Batheetha was classified as a medium-GI food (59), possibly due to the sugar (sucrose) added during its preparation. Khabisa and Balalet are Emirati sweet dishes that both contain a high amount of white flour and sugar and have a medium GI value (mean GI=67 and 63, respectively). The findings of this study advocate attention to the nutritive value and health aspects of traditional desserts when establishing dietary guidelines for the UAE. Traditional desserts should be consumed in moderation due to their medium to high glycaemic response.

In this study, we have demonstrated that the majority of test foods were classified as high GL, which is expected as most of the test foods had high GI. However, the GL value is dependent on food portion size which tend to vary greatly between countries and even within a country. The results presented here should therefore be used and interpreted with caution. We recommend that dietitians calculate their own GL values using the GI data provided.

A limitation of the current study was purchasing test foods $1 \mathrm{~d}$ before the test, and refrigerating them until use. Refrigeration has been suggested to affect the GI of foods through starch retrogradation and the formation of resistance starch, which reduces the amount of starch available for digestion and in turn might reduce the GI of the test foods ${ }^{(62,63)}$.

In conclusion, this study provides GI and GL values of eighteen locally consumed foods in the UAE. Determining the nutritional composition and the glycaemic response of Emirati traditional foods is important and key in assessing the dietary intake of the population which could be useful for health promotion and disease prevention. In addition, these tables could be used as a guide for nutrition therapy planning and dietary management for dietitians in the UAE and other Gulf Cooperation Council (GCC) countries. In addition, knowing the GI and GL values of traditional Emirati foods helps in developing better dietary guidelines and food choices for individuals living with diabetes and/or obesity.

\section{Acknowledgements}

The authors wish to thank all those who participated in this study.

The present study was funded by the Science and Technology Program of the Emirates Foundation for Philanthropy (ref. no. 2010/090). The Science and Technology Program of the Emirates Foundation for Philanthropy had no role in the design, analysis or writing of this article.

A. S. A. D. conceived and designed the experiments; M. N. M., E. O. O. analysed the data and reviewed the paper; A. S. A. D. and M. N. M. wrote the paper; A. S. A. D., M. N. M., F. T. A. M. and A. H. J. coordinated data collection; C. J. K. H. and L. C. I. contributed to drafting of the manuscript; C. J. K. H., L. C. I., A. H. J. and E. O. O. contributed to critical revision of the manuscript; A. S. A. D. contributed reagents/materials/analysis tools; all the authors read and approved the final version of the manuscript. None of the authors has any conflicts of interest to declare.

\section{References}

1. Jenkins DJ, Wolever TM, Taylor RH, et al. (1981) Glycemic index of foods: a physiological basis for carbohydrate exchange. Am J Clin Nutr 34, 362-366.

2. Food and Agriculture Organization/World Health Organization (1998) Carbohydrates in human nutrition. Report of a Joint FAO/WHO Expert Consultation FAO Food and Nutrition, paper no. 66. Rome: FAO.

3. Salmerón J, Ascherio A, Rimm EB, et al. (1997) Dietary fiber, glycemic load, and risk of NIDDM in men. Diabetes Care 20, 545-550.

4. Brand-Miller JC, Holt SH, Pawlak DB, et al. (2002) Glycemic index and obesity. Am J Clin Nutr 76, 281S-285S.

5. Ludwig DS (2002) The glycemic index: physiological mechanisms relating to obesity, diabetes, and cardiovascular disease. JAMA 287, 2414-2423.

6. Van Dam R, Visscher A, Feskens E, et al. (2000) Dietary glycemic index in relation to metabolic risk factors and incidence of coronary heart disease: the Zutphen Elderly Study. Eur J Clin Nutr 54, 726-731.

7. Aziz A (2009) The glycemic index: methodological aspects related to the interpretation of health effects and to regulatory labeling. J AOAC Int 92, 879-887. 
8. Rahelić D, Jenkins A, Božikov V, et al. (2011) Glycemic index in diabetes. Coll Antropol 35, 1363-1368.

9. Parillo M, Licenziati M, Vacca M, et al. (2012) Metabolic changes after a hypocaloric, low-glycemic-index diet in obese children. J Endocrinol Invest 35, 629-633.

10. Raatz SK, Torkelson CJ, Redmon JB, et al. (2005) Reduced glycemic index and glycemic load diets do not increase the effects of energy restriction on weight loss and insulin sensitivity in obese men and women. J Nutr 135, 2387-2391.

11. Alfenas RCG \& Mattes RD (2005) Influence of glycemic index/ load on glycemic response, appetite, and food intake in healthy humans. Diabetes Care 28, 2123-2129.

12. Schwingshackl L \& Hoffmann G (2013) Long-term effects of low glycemic index/load vs. high glycemic index/load diets on parameters of obesity and obesity-associated risks: a systematic review and meta-analysis. Nutr Metab Cardiovasc Dis 23, 699-706.

13. Goff L, Cowland D, Hooper L, et al. (2013) Low glycaemic index diets and blood lipids: a systematic review and meta-analysis of randomised controlled trials. Nutr Metab Cardiovasc Dis 23, 1-10.

14. Radulian G, Rusu E, Dragomir A, et al. (2009) Metabolic effects of low glycaemic index diets. Nutr J. 8, 1 .

15. Brouns F, Bjorck I, Frayn KN, et al. (2005) Glycaemic index methodology. Nutr Res Rev 18, 145-171.

16. Foster-Powell K \& Miller JB (1995) International tables of glycemic index. Am J Clin Nutr 62, 871S-890S.

17. Foster-Powell K, Holt SH \& Brand-Miller JC (2002) International table of glycemic index and glycemic load values: 2002. Am J Clin Nutr 76, 5-56.

18. Atkinson FS, Foster-Powell K \& Brand-Miller JC (2008) International tables of glycemic index and glycemic load values: 2008. Diabetes Care 31, 2281-2283.

19. Horwitz W (2003) Official Methods of Analysis of AOAC International. Gaithersburg, MD: AOAC International.

20. Dashti BH, Al-Awadi F, Khalafawi MS, et al. (2001) Nutrient contents of some traditional Kuwaiti dishes: proximate composition and phytate content. Food Chem 74, 169-175.

21. Al Nagdy S, Abd-El Ghani SA \& Abdel-Rahman M (1994) Chemical assessment of some traditional Qatari dishes. Food Chem 49, 261-264.

22. Wolever TM, Jenkins DJ, Jenkins AL, et al. (1991) The glycemic index: methodology and clinical implications. $A m J$ Clin Nutr 54, 846-854.

23. World Health Organization (2010) WHO guidelines on drawing blood: best practices in phlebotomy. Geneva: WHO. http://www. who.int/injection_safety/sign/drawing_blood_best/en/

24. Wolever TM (2003) Carbohydrate and the regulation of blood glucose and metabolism. Nutr Rev 61, S40-S48.

25. Abu Dhabi Food Control Authority (2014) A Photographic Atlas of Food Portions for the Emirate of Abu Dhabi. Abu Dhabi: Abu Dhabi Food Control Authority. https://www.adfca. ae/English/MediaCenter/Publications/Documents/atlas_en.pdf (accessed April 2017).

26. International Organization for Standardization (2010) Food Products-Determination of the Glycaemic Index (GI) and Recommendation for Food Classification. Geneva: ISO.

27. Arvidsson-Lenner R, Asp N-G, Axelsen M, et al. (2004) Glycaemic index. Relevance for health, dietary recommendations and food labelling. Food Nutr Res 48, 84-94.

28. Englyst HN, Veenstra J \& Hudson GJ (1996) Measurement of rapidly available glucose (RAG) in plant foods: a potential in vitro predictor of the glycaemic response. $\mathrm{Br} J$ Nutr $\mathbf{7 5}$, 327-337.

29. Pfeifer HH, Lyczkowski DA \& Thiele EA (2008) Low glycemic index treatment: implementation and new insights into efficacy. Epilepsia 49, 42-45.
30. Behall KM, Scholfield DJ \& Canary J (1988) Effect of starch structure on glucose and insulin responses in adults. Am J Clin Nutr 47, 428-432.

31. Hassan A, Elobeid T, Kerkadi A, et al. (2010) Glycemic index of selected carbohydrate-based foods consumed in Qatar. Int J Food Sci Nutr 61, 512-518.

32. Ali A, Al-Nassri HAS, Al-Rasasi B, et al. (2010) Glycemic index and chemical composition of traditional Omani breads. Int $J$ Food Prop 13, 198-208.

33. Liljeberg HG, Lönner CH \& Björck IM (1995) Sourdough fermentation or addition of organic acids or corresponding salts to bread improves nutritional properties of starch in healthy humans. J Nutr 125, 1503-1511.

34. De Angelis M, Rizzello CG, Alfonsi G, et al. (2007) Use of sourdough lactobacilli and oat fibre to decrease the glycaemic index of white wheat bread. $B r J$ Nutr 98, 1196-1205.

35. Novotni D, Ćurić D, Bituh M, et al. (2011) Glycemic index and phenolics of partially-baked frozen bread with sourdough. Int J Food Sci Nutr 62, 26-33.

36. Gobbetti M, Rizzello CG, Di Cagno R, et al. (2014) How the sourdough may affect the functional features of leavened baked goods. Int J Food Microbiol 37, 30-40.

37. Henry C, Lightowler H, Kendall F, et al. (2006) The impact of the addition of toppings/fillings on the glycaemic response to commonly consumed carbohydrate foods. Eur J Clin Nutr $\mathbf{6 0}$, $763-769$.

38. Flint A, Moller BK, Raben A, et al. (2004) The use of glycaemic index tables to predict glycaemic index of composite breakfast meals. Br J Nutr 91, 979-989.

39. Hatonen KA, Virtamo J, Eriksson JG, et al. (2011) Protein and fat modify the glycaemic and insulinaemic responses to a mashed potato-based meal. Br J Nutr 106, 248-253.

40. Henry CJ, Lightowler HJ, Kendall FL, et al. (2006) The impact of the addition of toppings/fillings on the glycaemic response to commonly consumed carbohydrate foods. Eur J Clin Nutr 60, 763-769.

41. Trinidad TP, Valdez DH, Loyola AS, et al. (2003) Glycaemic index of different coconut (Cocos nucifera)-flour products in normal and diabetic subjects. Br J Nutr 90, 551-556.

42. Fernandes G, Velangi A \& Wolever TM (2005) Glycemic index of potatoes commonly consumed in North America. J Am Diet Assoc 105, 557-562.

43. Soh N \& Brand-Miller J (1999) The glycaemic index of potatoes: the effect of variety, cooking method and maturity. Eur J Clin Nutr 53, 249-254.

44. Bahado-Singh PS, Riley CK, Wheatley AO, et al. (2011) Relationship between processing method and the glycemic indices of ten sweet potato (Ipomoea batatas) cultivars commonly consumed in Jamaica. J Nutr Metab 584832, 6.

45. Ek KL, Brand-Miller J \& Copeland L (2012) Glycemic effect of potatoes. Food Chem 133, 1230-1240.

46. Thorburn AW \& Brand JC (1987) Digestion and absorption of carbohydrate in Australian Aboriginal, Pacific Island and Western foods. Aust Aboriginal Studies 1, 61-64.

47. Perry T, Mann J, Mehalski K, et al. (2000) Glycaemic index of New Zealand foods. $N Z$ Med J 113, 140.

48. Wolever TM, Katzman-Relle L, Jenkins AL, et al. (1994) Glycaemic index of 102 complex carbohydrate foods in patients with diabetes. Nutr Res 14, 651-669.

49. Tahvonen R, Hietanen R, Sihvonen J, et al. (2006) Influence of different processing methods on the glycemic index of potato (Nicola). J Food Comp Anal 19, 372-378.

50. Liljeberg H \& Björck I (1998) Delayed gastric emptying rate may explain improved glycaemia in healthy subjects to a starchy meal with added vinegar. Eur J Clin Nutr 52, 368-371. 
51. Leeman M, Östman E \& Björck I (2005) Vinegar dressing and cold storage of potatoes lowers postprandial glycaemic and insulinaemic responses in healthy subjects. Eur J Clin Nutr $\mathbf{5 9}$, $1266-1271$.

52. Frei M, Siddhuraju P \& Becker K (2003) Studies on the in vitro starch digestibility and the glycemic index of six different indigenous rice cultivars from the Philippines. Food Chem $\mathbf{8 3}$, 395-402.

53. Jenkins DA, Jenkins A, Wolever TS, et al. (1984) The glycaemic response to carbohydrate foods. Lancet 324, 388-391.

54. Miller JB, Pang E \& Bramall L (1992) Rice: a high or low glycemic index food? Am J Clin Nutr 56, 1034-1036.

55. Kaur B, Ranawana V \& Henry J (2016) The glycemic index of rice and rice products: a review, and table of GI values. Crit Rev Food Sci Nutr 56, 215-236.

56. Pirasath S, Thayaananthan K, Balakumar S, et al. (2010) Effect of dietary curries on the glycaemic index. Ceylon Med J 55, 118-122.

57. Juansang J, Puttanlek C, Rungsardthong V, et al. (2012) Effect of gelatinisation on slowly digestible starch and resistant starch of heat-moisture treated and chemically modified canna starches. Food Chem 131, 500-507.

58. Lehmann U \& Robin F (2007) Slowly digestible starch - its structure and health implications: a review. Trends Food Sci Technol 18, 346-355.

59. Habib HM, Ali HI, Ibrahim WH, et al. (2011) Nutritional value of 10 traditional dishes of the United Arab Emirates. Ecol Food Nutr 50, 526-538.

60. Miller CJ, Dunn EV \& Hashim IB (2002) Glycemic index of 3 varieties of dates. Saudi Med J 23, 536-538.

61. Alkaabi JM, Al-Dabbagh B, Ahmad S, et al. (2011) Glycemic indices of five varieties of dates in healthy and diabetic subjects. J Nutr 10, 1.

62. Carreira MC, Lajolo FM \& de Menezes EW (2004) Glycemic index: effect of food storage under low temperature. Braz Arch Biol Technol 47, 569-574.

63. Burton P \& Lightowler H (2008) The impact of freezing and toasting on the glycaemic response of white bread. Eur J Clin Nutr 62, 594-599. 